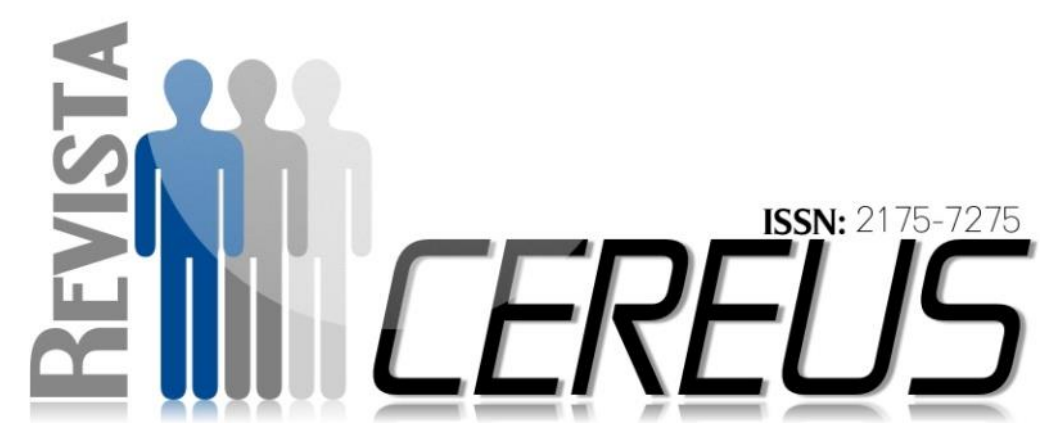

DOI: 10.18605/2175-7275/cereus.v9nep206-231.

\title{
HABEAS CORPUS DO NASCITURO
}

SOUZA, Camila Lopes Fernandes ${ }^{1}$

RESUMO

PAIVA, Jaqueline de Kássia Ribeiro de 2;

O presente estudo visa à elucidação dos Direitos Fundamentais à Vida e à Liberdade do nascituro na sociedade brasileira, analisando tanto sua teoria como sua aplicação nos Tribunais de Justiça Brasileiros. A Carta Magna em seu artigo 5o, caput menciona que é garantido, aos brasileiros e aos estrangeiros residentes no país, a inviolabilidade do direito à vida, à propriedade, à liberdade, entre outros. Além de estarem esculpidos na órbita brasileira, os Direitos Fundamentais tem a sua face internacional, conhecidos como Direitos Humanos, ressaltados na Declaração Francesa dos Direitos do Homem e do Cidadão, de 1779, qual define que "todos os homens nascem livres e são iguais nos seus direitos". Desse modo os Direitos Fundamentais e Universais outorgam aos seus titulares a

\footnotetext{
${ }^{1}$ Especialista em Direito Penal e Direito Processual Penal, pela Faculdade de Ciências Sociais Aplicadas de Marabá - FACIMAB. E-mail: clfmila@hotmail.com.

${ }^{2}$ Profa do curso de direito do Centro Universitário Unirg
} 
prerrogativa de impor os seus anseios em face das mazelas do Estado, a fim de buscar a efetividade dos seus Direitos. Assim sendo, a própria Constituição Brasileira estabelece remédios jurídicos para ampará-los, tendo em vista que os mesmos são o alicerce do ordenamento jurídico de um Estado Democrático de Direito. Portanto, o trabalho em comento tem como escopo assegurar os Direitos Fundamentais do nascituro, caso sua genitora se encontre presa, comentando para tanto o remédio constitucional eficaz.

Palavras chave: Direito Constitucional; Direito Penal; Habeas Corpus; Nascituro

\section{HABEAS CORPUS OF THE UNBORN CHILD}

\section{ABSTRACT}

The current study aims the elucidation of the Fundamental Rights to Life and to Liberty of the unborn child in the Brazilian society, looking at its theory and at its application in the Brazilian Courts of Justice. The Magna Carta, in its 5th article, caput, mentions that it is guaranteed to the Brazilians and to the foreigners living in this country, the inviolability to the rights to life, to property, to liberty and so on. Besides being sculpted to the Brazilian orbit, the Fundamental Rights have got their international face, known as the Human Rights, highlighted in the French Declaration of the Rights of Man and of the Citizen, 1779, which defines that "all men are born and remain free and equal in rights." Therefore the Fundamental and Universal Rights confer to their owners the prerogative of imposing their expectations in the face of the evils of the Estate, in order to pursue the effectiveness of their Rights. Consequently, the Brazilian Constitution establishes juridical remedy to support them, aiming that they are the basis of the legal order in a Democratic State based on the Rule of Law. Therefore, the 
present work has as a scope ensuring that the Fundamental Rights of the unborn, in case its genitor is arrested, commenting for this purpose the effective constitutional remedy.

Keywords: Constitutional Right; Criminal Law; Habeas Corpus; Unborn Child. 


\section{INTRODUÇÃO}

A Constituição Federal de 1988 no artigo $5^{\circ}$ traz os Direitos e Garantias Fundamentais Individuais. Entre os elencados estão o direito à Vida e à Liberdade, e como instrumento para eficácia destes direitos, está o devido processo legal e a ferramenta do Habeas Corpus. Quando texto Constitucional expressa "dos direitos e deveres individuais", em regra, associase à pessoa já nascida, contudo, quanto à pessoa que está por vir questiona-se se está inserida neste rol de direitos e garantias constitucionalizadas. As controvérsias sobre os direitos do nascituro têm sido constantes nos Tribunais Brasileiros e consequentemente na doutrina, principalmente no que tange a atribuição da personalidade jurídica ou não ao nascituro.

Desse modo, o presente Artigo se reveste da análise do Direito à Vida e à
Liberdade do nascituro, pois, em que pese estar ele em condições intrauterinas, examina-se se também Ihe é proporcionado o Direito do Desenvolvimento Saudável, corolário do Direito à Vida, e porque não o Direito à Liberdade, isto é, o Direito de ter um nascimento livre, afastado de quaisquer grilhões. O presente estudo tem como vertente principal a análise do nascituro quando sua genitora encontra-se tolhida em sua liberdade corpórea, isto é, quando está presa. Nesse contexto, busca-se compreender os direitos e garantias do nascituro, principalmente seus direitos fundamentais e sua dignidade.

Portanto, abordaremos estudos conceituais sobre a temática, tencionando o fomento da discursão da efetivação dos direitos do nascituro e o seu exercício.

\section{ASPECTOS DO NASCITURO}

\subsection{CONCEITO DE PESSOA}

Um dos grandes questionamentos da filosofia consiste em saber o que é uma pessoa. Em regra, a resposta está associada ao conjunto de certas características do ser humano, como um ser pensante e 
consciente de si mesmo, com domínio de linguagem, repleto de individualidade própria. Em que pese essas características não serem aplicadas a todos, podemos dizer que uma das expressões essenciais que dá singularidade à pessoa é ser única, irrepetível, racional, comunicativa e em permanente construção no campo das relações interpessoais.

Martha Chavedar de Souza Araújo, 2008, p. 77, mestra em filosofia, realizando um estudo sobre o Direito à Vida com foco em Peter Singer, filósofo e professor australiano, expõe o pensamento do filósofo da seguinte forma:

Peter Singer explica que a definição da expressão "ser humano" torna-se decisiva para se pôr em questão a defesa e a manutenção do direito à vida. Assim, tal expressão pode receber dois significados: o primeiro equivalente a "membro da espécie Homo sapiens" e o segundo, proposto por Joseph Fletcher, equivalente a "pessoa". Por pessoa entende-se todos aqueles que possuem indicadores de humanidade, na qual se incluem os seguintes: autoconsciência, autocontrole, senso de futuro, senso de passado, capacidade de relacionar-se com os outros, preocupação com os outros, comunicação e curiosidade.

A dificuldade em admitir o posicionamento de Singer, citado pela mestra, é que alguns mamíferos, Rev. Cereus, v. 9, n. edição esp, p.206-231, ago-dez./2017, UnirG, Gurupi, TO, Brasil. animais não-humanos, como gorilas e golfinhos, podem ocupar o "status" de pessoa, devido a dificuldade em auferir os "indicadores de humanidade" nos mesmos, pois, diante da dúvida, o melhor seria preservar a sua vida. Dworkin, 2009, p. 30, em que pese não fazer menção expressa ao posicionamento de Singer, o crítica, e admite filosoficamente a possibilidade de "porcos" serem considerados como pessoas, "ante à nova descoberta de que eles são mais inteligentes que os homens", chegando a conclusão de que, "filosoficamente, poderíamos acreditar que os porcos são pessoas, mas que os seres humanos não têm nenhuma razão para tratá-los do mesmo modo como tratam uns aos outros". Já em relações às discursões sobre o feto ser pessoa ou não, o autor expõe:

Uma vez mais, portanto, seria inteligente deixar de lado questão de saber se o feto é uma pessoa, não por tratar-se de questão irrespondível ou metafísica, como afirmaram muitos juízes e comentaristas, mas por demasiando ambígua para ser útil.

Já Mário Emílio Bigotte Chorão, citado por Maria J. A. Chinelato e Almeida, 2000, p. 101, esclarece a situação do nascituro, mencionando que: 
O cerne da questão consiste numa reflexão sobre 0 sentido da personalidade jurídica em íntima ligação com o conceito ontológico de pessoa. Esta reflexão, embora conte com o contributo científico da dogmática e da teoria geral do Direito, situa-se num nível de maior radicalidade, que revela da competência da filosofia do direito e da filosofia tout court. A decisão sobre a eventual identidade pessoal do embrião humano pertence também, de direito, à filosofia, mas não pode deixar de apoiar-se nos dados científicos da biologia, da embriologia, da genética, etc. Depois, estando em causa a tutela devida aos seres embrionários, alguma palavra terão a dizer a ética, a axiologia jurídica e a política do direito.

Em outro momento Chinelato

cita R. Limongi França, para trazer mais clareza à questão do nascituro ser ou não pessoa, relata:

(...) com apoio na doutrina aristotélico-tomista,

filosoficamente o nascituro é pessoa, porque já traz em si o germe de todas as características do ser racional. Sua imaturidade não é essencialmente diversa da dos recém-nascidos. O nascituro está para a criança como esta está para o adulto.

Assim o conceito de pessoa, uma inclusão de dignidade e respeito que atravessa o conceito humano, deve ser reservado ao ser humano e a todos aqueles que pertencem à espécie humana. Deste modo, o posicionamento de Singer mostra-se, data vênia, inadequado, em razão da possibilidade de vislumbrar animais como pessoas, não obstante a boa intenção de preservação destes. Já o pensamento de Dworkin se apresenta, apenas neste aspecto, consistente, ao expor que: "nossa convicção comum de que a vida humana, em qualquer forma, tem um valor sagrado, inerente" (2009, p. VII), valor este que nos remete à ideia de "dignidade", que nos torna valiosos. Contudo, salientamos que à convicção peculiar do filósofo, Dworkin, é de que o feto/nascituro não é pessoa. E por fim, o pensamento exposto por Chinelato fundamenta-se com razão, principalmente porque, analisa o nascituro com o olhar de dignidade, ao expressar que uma vida humana já nascida e aquela que está por vir se tratam de pessoa e por isso merecem a devida tutela.

$\mathrm{Na}$ acepção jurídica o termo pessoa torna-se um pouco mais objetivo. Da mesma forma que não existe direito sem sociedade, não existe sociedade sem pessoas. Assim, 0 conceito de pessoa, como sujeito de direitos que se interagem dentro de uma sociedade é melhor definido por Teixeira de Freitas, citado por Pablo Stolze, que define pessoa física ou natural como um ente de "existência visível", 2011, p. 125. Já Maria Helena 
Diniz, citando Diego Espín Cánovas, acrescenta:

Para a doutrina tradicional "pessoa" é o ente físico ou coletivo suscetível de direitos e obrigações, sendo sinônimos de sujeitos de direito. Sujeito de direito é aquele que é sujeito de um dever jurídico, de uma pretensão ou titularidade jurídica, que é o poder de fazer valer, através de uma ação, o não cumprimento do dever jurídico, ou melhor, o poder de intervir na produção da decisão judicial. (pg. 129, 2011).

O conceito de pessoa está umbilicalmente ligado ao conceito de personalidade - atributo essencial de uma pessoa -, que Sílvio de Salvo Venosa, 2008, p. 131, assim o define como sendo "a projeção da personalidade íntima, psíquica de cada um; é projeção social da personalidade psíquica, com consequências jurídicas". Já Caio Mário da Silva Pereira citando Planiol, Ripert e Boulanger, 2005, p. 214, relata como "atributo inseparável do homem dentro da ordem jurídica, qualidade que não decorre do preenchimento de qualquer requisito psíquico e também dele inseparável".

Assim destacamos que 0 atributo da personalidade é estendido a todo ser humano, entendimento que se obtém do art. 1ํ do Código Civil, o qual afirma que "toda pessoa é capaz de direitos e deveres na ordem civil" (grifo nosso). Já a capacidade de exercê-la é plena para uns e limitada para outros, assim definido por Carlos Roberto Gonçalves, 2011, p. 95 e 96, que:

(...) a que todos têm, e adquirem ao nascer com vida, é a capacidade de direito ou de gozo (...), essa capacidade é reconhecida a todo o ser humano, sem qualquer distinção (...), a capacidade de fato, também denominada capacidade de exercício ou de ação, que é a aptidão para exercer por si só, os atos da vida civil.

A capacidade e personalidade se completam, à medida que questiona-se: valer-se-á personalidade sem a capacidade de exercê-la? Certamente que não, razão pela qual do que vale ter direitos e não concretizá-los. Todavia, aqueles que não possuem a capacidade para 0 exercício de direito, como o nascituro e amentais, devem ser representados pelos pais e curadores, respectivamente, para terem resguardados seus direitos, pois não tem capacidade perante o Estado. Aquele que possui as duas capacidades citadas anteriormente, tem capacidade plena, não precisam de assistência ou de representação, como no caso da pessoa maior de 18 anos. Malgrado o Código Civil atribuir personalidade a pessoa ao nascer com 
vida, assim exposto no art. $2^{\circ}$, primeira parte, do diploma legal, o nascituro, no entendimento sistemático e coerente do ordenamento jurídico brasileiro,

\subsection{TEORIAS SOBRE O INÍCIO DA VIDA}

As conhecidas dúvidas sobre o início da vida, e ainda sobre a vertente do nascituro ser considerado uma pessoa ou não, são questões por demais ambíguas, de aspectos distintos que percorrem desde a medicina, filosofia, religião, moral entre outros. Desses fatos surgem debates calorosos sobre o tema, inclusive quando este episódio irradia efeitos em relação ao aborto. A medicina não é pacífica sobre em que momento exatamente a vida se inicia, mas até o momento é inegável que um embrião, implantado no útero e ocorrido a nidação ${ }^{3} 4$, constitui como um dos primeiros estágios de formação do ser humano. Também é inquestionável que o embrião possui um patrimônio genético próprio que irá reger o seu futuro desenvolvimento.

\footnotetext{
${ }^{3}$ Caso não entendêssemos assim, que a vida começa com a concepção estando condicionada nidação frustraríamos o ramo da ciência biológica, ao passo que as éticas de fertilização in vitro e congelamento de embriões humanos e a pesquisa e terapia da utilização de células tronco, qual se permite a utilização de embriões em pesquisas científicas, contribui bastante para o controle e extirpação de
}

como logo veremos, também está incluso neste conceito.

Para alguns pesquisadores 0 início da vida se dá quando há junção do gameta feminino com o gameta masculino, e estes, porém, sozinhos são apenas partes do corpo humano aptos a reprodução, que por sua vez representam relevância ético-jurídica, pois estão na "sequência de reprodução das pessoas".

Destarte, logo após esta junção dos gametas inicia-se um processo irreversível, que, em regra, resultará numa criança. Nesse sentido, está caracterizado um novo ser, um genoma novo, diferenciado dos seus progenitores e de todos os outros existentes, o que o torna, desde o ventre de sua mãe, um ser individualizado, assim é o que relata os

várias doenças utilizando métodos relacionados a material genético humano, neste pondo a ciência jurídica lhe resta atribuir outro conceito de início da vida.

4 "O termo nidação refere-se ao momento de implantação de um embrião de mamífero na parede uterina que ocorre durante a blástula." 
principais experts na área, assim colacionamos:

Para a farmacóloga leda Verreschi, professora de endocrinologia da Universidade Federal de São Paulo (Unifesp), os embriões congelados são o mesmo que crianças. 'O potencial humano está lá; foi congelado, mas está lá', defendeu leda, em um debate recente sobre as células-tronco embrionárias na Câmara Municipal de São Paulo. A advogada Maria Garcia, professora de biodireito constitucional da Pontifícia Universidade de Católica (PUC) de São Paulo, concorda. 'São seres humanos sem dúvida. Se toda vida começa com óvulo fecundado, como poderiam não ser? É só por cinismo ou arrogância que alguém pode dizer que não sabe onde começa a vida.

Já o início da vida humana, no campo filosófico, afirma Dworkin, de acordo com a "convicção comum tem um valor sagrado" (2009, p. VII). Deste modo, a sociedade imprime esse valor diante das questões sobre a vida ou morte, para que não 0 seja desrespeitado - um valor eminentemente religioso. Destarte, afirma o autor que "as pessoas não poderão pensar que um feto tem interesses próprios a partir do momento da concepção, porque não existe ainda tal pensamento no feto" (2009, p. X). Notadamente o filósofo afirma que, para o feto ter 'interesses próprios', necessariamente ele precisa ter "cultura" para entender de fato o que lhe são seus interesses/direitos. Assim, tendo em vista que o feto encontra-se no estado intrauterino, há uma ausência de cultura humana que lhe insira valores, sentimentos, noções, diretrizes entre outros.

Não obstante à afirmação do douto filósofo, é necessário tecer algumas considerações relevantes e notórias em nosso meio; imaginemos uma criança, ainda no primeiro ano, brincando com amiguinhos, quando algo Ihe chama atenção. Logo traz consigo à sua esfera de domínio e quando outra criança quer agregar aquele mesmo objeto ao seu domínio, de forma instantânea, a primeira criança o nega, seja em palavras ou de modo comportamental.

Destaca-se que em nenhum momento seus pais ou responsáveis tiveram que the ensinar o instituto da propriedade/posse sobre a coisa ou qualquer outro valor semelhante, para que a criança assim haja - negando aquele objeto à outra criança -, simplesmente e notoriamente as crianças agem desta forma, perfazendo algo inerente à sua pessoa, e porque 
não dizer 'perfazendo algo natural de sua essência'.

Desta forma, em que pese os argumentos supracitados, o nascituro tem a real noção do que the interessa/direitos, tanto é verdade que nos primeiros anos de vida expressa seus interesses intrínsecos, sem qualquer ensinamento para isto. Assim, em relação ao feto e também aos amentais, falta-Ihe forças para exprimir seus interesses ante o seu estado ainda em desenvolvimento, ou ante a falta de discernimento, respectivamente, necessitando assim de outrem que o faça.

Outro momento, diz Dworkin, "infligir dor a um feto que já possui um sistema nervoso suficientemente desenvolvido também contraria frontalmente seus interesses" (2009, p. 21), assim o nascituro somente tem tal consciência quando a gestante encontra-se em um estágio avançado da gravidez, e essa sensação de dor, dizem os experts, ocorre por volta de 24 (vinte e quatro) semanas de gestação ${ }^{5}$,

5 "De acordo com um estudo publicado nesta sextafeira e divulgado pelo jornal inglês The Guardian, o feto humano não sente dor antes de 24 semanas de concepção. As conexões nervosas no cérebro do feto não são formadas antes desse período. O Royal não sabendo, contudo, dizer o momento exato.

Assim sendo, o filósofo questiona, que um organismo que nunca teve maturidade cervical, ainda assim, pode ter interesses.

Sem dúvidas, existem muitos atos que afrontam o nosso interesse e que certamente não nos causam dor física propriamente dita, por exemplo, a escolha de outra pessoa ao cargo o qual você almeja, ou ser demandado em um processo, são acontecimentos que nos causam certo constrangimento, mas não nos causam a sensação de dor, e mesmo assim não quer dizer que isto não se refere ao nosso interesse. Da mesma forma é o nascituro, não obstante a ausência de maturação cervical nos primeiros estágios da formação, o mesmo tem o interesse no seu desenvolvimento pleno e no seu nascimento com vida em liberdade.

Mormente, com avanço da medicina, pode-se afirmar que, desde o começo da gestação, os sentimentos da genitora afetam o nascituro, visto que o ele está igualmente exposto aos

College of Obstetricians e Gynaecologists (Faculdade Real de Obstetras e Ginecologistas), da Inglaterra, também descobriu que a consciência não é formada no período." 
mesmos hormônios que ela, razão pela qual se a genitora se assusta, fica nervosa ou ansiosa, o seu corpo humano libera substâncias/hormônios que serão absorvidas pelo nascituro, via cordão umbilical. Ademais, de acordo com o entendimento do $\mathrm{Dr}$. Eliezer Berenstein, médico do Hospital Israelita Albert Einstein, do Estado de São Paulo, acredita-se que, desde a concepção, o nascituro tem memórias, pois "mesmo antes que haja neurônios, as células devem ter uma maneira de registrar quimicamente 0 que lhes acontece. Isto ajuda o embrião a não repetir experiências ruins", citado pela Dr. Ana Júlia Couto de Alencar, 2001, p. 58, médica com especialização em pediatria e habilitação em Neonatologia pela Sociedade Brasileira de Pediatria.

Diante disso, no ordenamento jurídico brasileiro ao longo dos séculos surgiram três teorias para justificar o cenário jurídico relacionado ao nascituro; a teoria natalista, a teoria concepcionista e a teoria condicional, assim Carlos Roberto Gonçalves, 2011, p. 103, esclarece:

A natalista afirma que a personalidade civil se inicia com o nascimento com vida; a da personalidade condicional sustenta que o nascituro é pessoa condicional, pois a aquisição da personalidade acha-se sob a dependência de condição suspensiva, o nascimento com vida, não se tratando propriamente de uma terceira teoria, mas sim de um desdobramento da teoria natalista, visto que também parte da premissa de que a personalidade tem início com o nascimento com vida; e a concepcionista admite que se adquire personalidade antes do nascimento, ou seja, desde a concepção, ressalvados apenas os direitos patrimoniais, decorrentes de herança, legado e doação, que ficam condicionados ao nascimento com vida.

No direito posto, o Código Cível dispõe no art. $2^{\circ}$ que "a personalidade civil da pessoa começa do nascimento com vida, mas a lei põe a salvo, desde a concepção, os direitos do nascituro". Desta forma, a lei civilista não confere ao nascituro a personalidade ${ }^{6}$, qual somente Ihe é atribuída com o nascer com vida, aplicando assim a teoria natalista, oriunda do direito romano. Percebe-se que, diante do artigo subscrito, hodiernamente, o nascituro não é considerado sujeito de direito, contudo é carecedor de proteção legal, pois provavelmente nascerá com vida,

\footnotetext{
ser denominada com termo de personalidade - foi, em seguida, longamente discutida e aprofundada pelos estóicos" (2007, p. 16).

${ }^{6}$ Comparato ensina que, "'a oposição entre a mascará teatral (papel de cada indivíduo na vida social) e a essência individual de cada ser humano - que veio a

Rev. Cereus, v. 9, n. edição esp, p.206-231, ago-dez./2017, UnirG, Gurupi, TO, Brasil.
} 
e caso aconteça, os seus direitos retroage ao momento de sua concepção. Este posicionamento é adotado pela doutrina tradicional, e também pelos positivistas, de que 0 início da personalidade se origina do ordenamento jurídico, assim inicia-se do o nascimento com vida, como no caso do nosso llustre autor Sílvio de Salvo Venosa.

Percebe-se que, para se adquirir a personalidade, o Código Civil estabelece que é necessário não apenas nascer, como também nascer com vida. Este primeiro refere-se ao momento em que o nascituro é separado da gestante, seja de forma natural ou com instrumentos que os auxiliem, isto é, que rompam a unidade biológica. Já o segundo ocorre quando o nascituro realiza a troca oxicarbônica com ambiente que o cerca, assim cumprido estes requisitos o nascituro adquiriu personalidade, mesmo que venha falecer minutos depois.

Todavia, por outro lado, parte da doutrina tradicional e a contemporânea adotam a teria concepcionista, tendo como fundamento não somente 0 art. $2^{\circ}$ do Código Civil, mas também a interpretação sistêmica das leis constitucionais e infraconstitucionais, bem como Tratados Internacionais, assim Pablo Stolze, 2011, p. 127, afirma que:

A teoria concepcionista, por sua vez, influenciada pelo Direito francês, contou com diversos adeptos. Segundo essa vertente de pensamento, 0 nascituro adquiriria personalidade jurídica desde a concepção, sendo, assim, considerado pessoa. É a posição de TEIXEIRA DE FREITAS, seguido por BEVILÁQUA, LIMONGI FRANÇA e FRANCISCO AMARAL SANTOS. Essa linha doutrinária rende ensejos inclusive a se admitirem efeitos patrimoniais, como 0 direito aos alimentos, decorrentes da personificação do nascituro.

A autora Silmara J. A. Chinelato e Almeida, 2000, p. 168, em sua belíssima obra, Tutela Civil do Nascituro, adota a teoria concepcionista, afirmando:

Não há meia personalidade ou personalidade parcial. Mede-se ou quantifica-se a capacidade, não a personalidade. Por isso se afirma que a capacidade é a medida da personalidade. Esta é integral ou não existe. Com propriedade afirma Francisco Amaral: 'Pode-se ser mais ou menos capaz, mas não se pode ser mais ou menos pessoa'.

Nesse sentido, a autora é bastante clara ao ressaltar que personalidade é um valor atribuído à pessoa, e diante disso não pode ser negado a uma pessoa em formação. Ressalte-se que o Código Civil 
diferencia os sujeitos capazes e os incapazes - relativamente e absolutamente -, contudo em nenhum momento retira-lhes a personalidade, mas aufere uma restrição de sua capacidade, e, por consequência, deve ocorrer o mesmo com o nascituro, de modo que sequer cogite em não consideração de personalidade, mas sim uma limitação de sua capacidade, necessitando, assim, de outrem 0 represente.

Assim há autores que entendem que o nascituro possui personalidade condicional; "sustentam que a personalidade do nascituro conferiria aptidão apenas para a titularidade de direitos personalíssimos (sem conteúdo patrimonial), uma vez que os direitos patrimoniais estariam sujeitos a vida (condição suspensiva)", assim citado por Pablo Stolze, 2011, p. 127. Já a doutrina contemporânea, a nosso ver, é uníssona ao reconhecer ao nascituro a personalidade jurídica, não obstante, a llustre autora Maria Helena Diniz atribuir ao nascituro à personalidade jurídica formal, só adquirindo a personalidade jurídica material com 0 nascimento com vida, contudo, afirma que os direitos de índole existencial pertencem ao nascituro, afastando apenas os direitos de ordem patrimonial. Posicionamento criticado por Chinelato, 2000, p. 169:

Não há também de falar em
'personalidade condicional',
erro em que incorrem os que
identificam personalidade e
capacidade. Conforme
demonstramos, a
personalidade do nascituro não
é condicional; apenas certos
efeitos e de certos direitos
dependem do nascimento com
vida, notadamente os direitos
patrimoniais materiais, como a
doção e a herança. Nesses
casos, o nascimento com vida
é elemento do negócio jurídico
que diz respeito à sua eficácia
total, aperfeiçoando-a.

A questão abordada é bastante controversa, a vertente de que o nascituro possui os mesmos direitos que uma pessoa/criança já nascida para muitos gera dúvidas, mas em que pese os posicionamentos contrários, acreditamos que inafastável é o atributo da personalidade ao nascituro, assim como discorre Chinelato, e diante disso devem ser assegurados a ele todos os direitos de uma pessoa já nascida, não apenas alguns, mas todos, inclusive 0 da liberdade. Pois se assim não fosse, ao analisarmos o ordenamento jurídico brasileiro, haveria papéis antagônicos, onde uma norma aufere apenas uma expectativa de direito (art. $2^{\circ}$ do CC) e outras tantas, o torna sujeito de direito, como: a Constituição, art. 5º, o qual relata que "todos são iguais perante a 
lei, sem distinção de qualquer natureza (...)"; o Estatuto da Criança e do Adolescente, que em seu art. $7^{\circ}$ e $8^{\circ}$ assegura a tutela integral ao nascituro; a Lei 8.560/1992, artigo $7^{\circ}$, na qual é assegurado 0 direito a alimentos provisionais ou definitivos do reconhecido, no caso ao nascituro; a Lei de Alimentos Gravídicos, 11.804/2008, que menciona prestações necessárias ao custeio de gastos desde a concepção ao nascimento do nascituro; o nascituro também poderá ser objeto de reconhecimento de filiação assim exposto no art. 1.609, § único, do Código Civil, e ainda, Ihe pode ser nomeado um curador, caso o pai faleça, e a gestante não ter o poder familiar, prescrito no art. 1.779 do CC.

A tutela dos direitos do nascituro também é contemplada no âmbito internacional. O Tratado de São José da Costa Rica, art. 3ํ e 4.1ํㅡㄹ , de maneira clara e expressa adota a teoria concepcionista. A Declaração Universal dos Direitos Humanos (art. $1^{\circ}$ ), reconhece o nascituro como sujeito de direito. Conclui-se que o Código Civilista adotou a teoria natalista apenas por questão de praticidade como definiu Clóvis Beviláqua (1975, p. 178), conquanto 0 Ordenamento Jurídico Brasileiro, em diversos pontos, aplica a teoria concepcionista, reconhecendo o nascituro como sujeito de direito. Vulgarmente poder-se-ia falar que o Código Civil "se casou aquela, mas tem como amante está".

Portanto, a situação jurídica do nascituro é tema bastante discutível em nossos Tribunais, nas doutrinas e na vida acadêmica - o que se agora faz -, restando à razoabilidade e à proporcionalidade contextualizar o nascituro em nosso ordenamento jurídico, juntamente com a biologia da vida. Por conseguinte, com prudência certamente podemos afirmar que não há de permitir quaisquer agressões à dignidade da pessoa humana, seja em qual estágio for e, portanto, qualquer circunstância que implique violação aos direito do nascituro deve ser afastada de plano.

\section{3 - POSSIBILIDADE DE IMPETRAR A AÇÃO DE HABEAS CORPUS AO NASCITURO ANTE A PRIVAÇÃO DE LIBERDADE DE SUA GENITORA}

Destarte, como vimos nos tópicos acima, a teoria natalista, adotada apenas pelo código civil, não se sustenta, pois à medida que se 
reconhece direitos ao nascituro, a atribuição da personalidade a este ser é uma consequência natural. Desta forma, este posicionamento civil merece reforma, nas palavras de Silmara J. A. Chinelato e Almeida, 2000, p. 350; "propomos que o Código adote a orientação do Esboço de Teixeira de Freitas, considerando que a personalidade se inicie com a concepção e o nascituro seja pessoa por nascer".

Ademais, além de todo o arcabouço de fundamentos para definir nascituro como sujeito de direito, valemo-nos da interpretação gramatical, um dos métodos utilizado para interpretação das normas, que consoante Barroso (1999, p. 129) deve ser o primeiro e o último método a ser empregado para que se tenha uma perfeita compreensão da norma. Assim, quando no deparamos com 0 art. $2^{\circ}$ do Código Civil, vemos que o artigo definido "os" antes de "direitos" determina este substantivo, sem mencionar qualquer taxatividade, porque assim não há. Desta forma, o nascituro não é apenas um objeto de tutela pelo ordenamento jurídico, mas sim um sujeito de direito. Nesse sentido a ele é dado o direito à vida, à saúde, à liberdade, à propriedade entre outros direitos fundamentais descritos tanto na Constituição quanto nas leis infraconstitucionais e tratados internacionais.

Assim, partindo da premissa que o nascituro é pessoa, detentor, portanto, de direitos e garantias constitucionais, não se coaduna com o pensamento que a genitora e o nascituro são "um só", sendo, portanto, pessoas diferentes, com características próprias, de modo que cada um é repleto de individualidade e personalidade intrínsecas de cada ser. Todavia, quando observamos a genitora do nascituro sendo tolhida em sua liberdade, constatamos uma ilegalidade neste encarceramento, não porque, em regra, a genitora está sob o manto da ilegalidade, mas sim porque o nascituro encontra-se lesado em seus direitos da personalidade, visto que esta privação vai de confronto à norma, prescrito no art. 5ㅇ, XLV, da Constituição Federal, qual menciona:

Nenhuma pena passará da pessoa do condenado, podendo a obrigação de reparar o dano e a decretação do perdimento de bens ser, nos termos da lei, estendidas aos sucessores e contra eles executadas, até o limite do valor do patrimônio transferido.

Neste diapasão, submeter o nascituro à condenação de sua genitora, certamente se está infringindo 
o princípio da pessoalidade ou da intranscendência da pena, pois somente a pessoa que foi condenada poderá cumprir a sanção penal imposta pelo Estado, de forma que se a genitora fora condenada, em nada corresponde à pessoa do nascituro, visto a premissa se trata de personalidades distintas. Houve-se o tempo em que a pena atingia as pessoas próximas do condenado, contudo, mormente, esta responsabilidade pertence apenas ao condenado, melhor esclarecido por Júlio Fabbrini Mirabete e Renato M. Fabbrini, na obra Manual de Direito Penal, parte geral, pg. 232, 2013:

Devem existir nas penas várias personalidade, proporcionalidade e inderrogabilidade. O princípio da legalidade consiste na existência previa de lei para a imposição da pena (nulla poena sine lege) previsto no art. $1^{\circ}$ do Código Penal. A característica da personalidade referre-se à impossibilidade de estender-se a terceiros a imposição da pena. Por isso, determina-se que "nenhuma pena passará da pessoa do condenado" (art. $\mathbf{5}^{\circ}, \quad \mathrm{XLV}$, primeira parte, da CF), proibindose, por exemplo, as penas infamantes. A nova Constituição, porém, prevê a cominação de pena de "perda de bens" (art. 50, XLVI, b), permitindo expressamente que a decretação do perdimento de bens possa ser, nos termos da lei, estendida aos sucessores e contra eles executada, até o limite do valor do patrimônio transferido (art. $X L V$, segunda parte). A exceção mutila 0 princípio da personalidade da pena. Os efeitos secundários da pena de prisão em relação aos dependentes do criminoso são corrigidos com medidas sociais (auxilio-reclusão, descontos na remuneração do sentenciado etc) deve haver, ainda, proporcionalidade entre o crime e a pena; cada crime deve ser reprimido com uma sanção proporcional ao mal por ele causado. Essa característica, entretanto, é abrandada no direito positivo: a Constituição Federal determina que "a lei regulará a individualização da pena" (art. 5०, XLVI), e o Código Penal refere-se, quando da aplicação da pena, aos antecedente, à conduta social, à personalidade do agente (art. 59), à reincidência (art. $61, \mathrm{I})$ etc. Por fim, a pena deve ser inderrogável: praticado o delito, a imposição deve ser certa e a pena cumprida. Tal caráter também é suavizado em várias situações, conforme a lei penal. São os casos da suspensão condicional, do livramento condicional, do perdão judicial, da extinção da punibilidade etc. (grifo nosso).

Ademais, quando nos deparamos com o cerceamento de liberdade da genitora do nascituro, certamente está Ihe tolhendo o "direito de nascer livre", assegurado na Declaração Universal dos Direitos Humanos, bem como, na Convenção Americana sobre Direitos Humanos, pois, como poderia uma pessoa (nascituro) nascer livre tendo sua genitora presa. Questiona-se, como pode ter o nascituro o desenvolvimento 
saudável estando em condições totalmente insalubres, consoante dados apontados no Relatório realizado pelo Centro Pela Justiça e pelo Direito Internacional (CEJIL) e pelas entidades que constituem o Grupo de Estudos e Trabalho Mulheres Encarceradas, de 2007.

Portanto, no caso em que a gestante está cumprindo pena restritiva de liberdade, confronta-se direitos fundamentais do nascituro, pois analisando a premissa de que o nascituro é ser distinto de sua genitora, visto que possui patrimônio genético próprio, bem como, a premissa de que a pena não passará da pessoa do condenado, chegamos à tese que o nascituro é uma pessoa sujeitos de direitos e deveres e, portanto deve ser resguardado o seu direito à vida, assim como à liberdade. Deste modo, todo tolhimento a estes direitos e garantias, ora constitucionalizados, devem ser extirpados, e caso sua genitora encontrar-se privada de sua liberdade, o instrumento a ser utilizado é o Habeas Corpus, pois o nascituro se encontra, no caso em comento, sob o manto da ilegalidade, razão pela qual este instrumento assegura 0 direito ao nascimento com liberdade.
Ademais, em virtude das falhas do nosso sistema prisional, acima relatadas, há os que entendem que na verdade há sim o direito de interposição de outra ação, mas no caso em comento seria Mandado de Segurança, para assegurar o direito à vida, à a saúde e à segurança, bem como, o direito ao nascimento livre, advertimonos, contudo, que, em que pese este posicionamento, esta medida jamais atingirá o princípio da dignidade da pessoa humana, pois somente lhe será dado o direito de nascer livre e somente construiremos uma sociedade livre, um dos objetivos da Carta Magna, se o nascituro de fato nascer livre, no seio de sua família, com amor, conforto e proteção que sua família lhe dá, somente assim estaremos cumprindo de modo eficaz o princípio da dignidade da pessoa humana.

Nota-se que tal medida, o habeas corpus, está sendo concedido para as mulheres gestantes, tendo em vista os direitos do nascituro, como aqui fundamentado, bem como para as mulheres em estado puerperal e mães com filhos menores que 12 (doze) anos, de acordo com a Segunda Turma do Supremo Tribunal Federal (HC 143641). 
E, caso a criança precise de outra medida assecuratória aos seus direitos, valer-se-á de outra medida, pois a finalidade desta medida é assegurar 0 direito à liberdade, bem como, o desenvolvimento saudável e à vida do nascituro

Acrescenta-se que qualquer pessoa pode ingressar com a ação, mediante atestado médico ou outro documento probante, devendo, neste caso, o nascituro ser representado, em especial pela genitora, tendo em vista que o nascituro ainda é incapaz deve se representar em juízo, necessitando assim de outrem que o faça, assim como preceitua art. 71 e 72, ambos do CPC c/c art. $3^{\circ}, \mathrm{CC}$, pois em que pese ser titular dos direitos, não tem capacidade para atuar perante o Poder Judiciário, necessitando assim de um representante, fato este que se enquadra como termo inicial da medida, já o termo final resta estabelecido com o nascimento da criança, ou caso for, a data do aborto espontâneo ou provocado, ou ainda, quando cessar os cuidados com a criança, conforme entendimento do STF no HC 143641.

Aliás, em relação à concessão da ordem resta o aparente conflito com a pena restritiva de liberdade da genitora, pois, neste caso questiona-se; a medida valerá como interrompida da pena ou como contagem de pena? A resposta é clara e sucinta: nenhuma das alternativas! A genitora terá a sua pena de privação de liberdade por domiciliar, sem prejuízo de outras medidas alternativas previstas no artigo 319 do Código de Processo Penal, e ao terminar este casuístico ela retornará a cumprir normalmente sua medida, evitando assim uma "indústria de genitoras profissionais a fim de evitar o cumprimento da pena de privações de liberdades brasileiras. Destarte, temos que ter em vista que se concede a liberdade a genitora em prol de um bem maior.

E mais, destaca-se que é dever do Estado em executar a pena ora imposta à genitora do nascituro, contudo é direito do nascituro nascer livre, de modo que nesta contenda temos que nos valer dos princípios da proporcionalidade quanto da razoabilidade, pois se indaga; é razoável uma pessoa nascer sob grilhões, sendo que tem o direito de nascer livre?. Ainda, é uma medida proporcional conceder a liberdade limitada à genitora do nascituro para que assim possa cuidar de uma pessoa que esta por vir? Sobre estas questões 
que se assiste razão ao Habeas Corpus do nascituro, pois visa assegurar 0 nascimento livre do nascituro e sua dignidade como pessoa, bem como tutelar seus direitos fundamentais, razão pela qual se constitui a tutela de um bem maior que está por vir.

Destarte, no ano de 2007 o Tribunal de Justiça do Espírito Santo julgou um habeas corpus impetrado pela Coordenação de Direitos Humanos da Defensoria Pública do Estado do Espírito Santo, qual resultou na seguinte ementa:

HABEAS CORPUS AÇAO PROPOSTA PELA GENITORA DO NASCITURO FUNDAMENTANDOSE NO DIREITO CONFERIDO E ELE DE NASCER DIGNAMENTE ATENDIMENTO PRÉ E PÓS NATAL - NASCIMENTO EM LOCAL ADEQUADO COM A DEVIDA ASSISTÊNCIA MÉDICA. ORDEM CONCEDIDA. À luz do artigo $2^{\circ}$ do Código Civil, temos que a personalidade civil do homem começa do nascimento com vida. Entretanto, expressamente dispõe o artigo que desde a concepção, os direitos do nascituro são postos a salvo. Dessa forma, resta claro que, havendo qualquer dano ou ameaça de dano ao seu bem-estar físico ou psíquico, ao nascituro cabe proteção. No presente caso justa se faz a concessão da ordem para garantir o direito do paciente ao nascimento com vida e em condições dignas e saudáveis, com observância no princípio da dignidade da pessoa humana. ORDEM CONCEDIDA para garantir um tratamento pré e pós-natal eficiente e imediato, bem como um

Rev. Cereus, v. 9, n. edição esp, p.206-231, ago-dez./2017, UnirG, Gurupi, TO, Brasil. parto digno à gestante, em local adequado e salubre. (TJ-ES - HC: 100070002991 ES 100070002991, Relator: ADALTO DIAS TRISTÃO, Data de Julgamento: 28/03/2007, SEGUNDA CÂMARA CRIMINAL, Data de Publicação: 09/05/2007) (grifo nosso).

Assim o Tribunal concede a ordem protetiva, contudo não liberatória ao nascituro de Karita Regina Chaves dos Santos, que foi condenada a pena 14 (quatorze) anos de reclusão e 80 (oitenta) dias-multa, e, 4 (quatro) meses de detenção, pelo crime de roubo e de falsa identidade, em 29 de janeiro de 2007, que cumpre pena desde o dia do fato delituoso em 19 de agosto de 2006, ainda fora the negado o direito de recorrer em liberdade.

Note-se que, data vênia, o Tribunal inovou no dispositivo do writ (concessão de assistência médica), pois até o momento a única finalidade do mandamus é auferir liberdade àquele que se encontra privado, ou na eminência de tê-la tolhida. Contudo, de acordo com o dispositivo do referido acórdão, a Câmara foi omissa, totalitária, porque fundamentou a efetivação dos direitos do nascituro e não concedeu a principal medida, qual seja, a liberdade para se aguardar o nascimento com vida. 
O Julgado, em que pese à boa intenção da Câmara em tutelar os direitos do nascituro, não cumpriu de forma eficaz e digna os direitos do nascituro, pois apenas conferiu medidas protetivas à sua genitora e a sua pessoa, mas não para que nasça em liberdade o nascituro, deixando assim a desejar porque reconheceu todos os atributos da personalidade ao nascituro, conquanto no momento de

\section{CONSIDERAÇÕES FINAIS}

Diante do exposto podemos perceber que as controvérsias que cercam a respeito do nascituro ser considerado ou não como pessoa, e consequentemente ter ou não personalidade jurídica, são constantes nas doutrinas, irradiando reflexos na jurisprudência brasileira. Em consonância com a narrativa, percebese que 0 art. $2^{\circ}$ do diploma cível, data vênia, é contraditório, na proporção que afirma que 0 nascituro terá a personalidade com o nascimento com vida, contudo na segunda parte do dispositivo, reconhece os direitos e status ao nascituro, não perfazendo qualquer restrição, referindo genericamente aos direitos que são lhe efetivá-los, retrocede. Deste modo, reconheceu a personalidade ao nascituro e apenas conferiu a proteção aos seus direitos, tais como, direito à vida, ao nascimento em condições salubres e livre. No melhor entendimento, o Julgado no aspecto formal conferiu o habeas corpus e materialmente conferiu um mandado de segurança.

atribuídos nos artigos subsequentes e esparsos, do código em comento.

Assim na medida em que se reconhece ao nascituro direitos: à vida, à saúde, à imagem, à honra, entre tantos outros, o reconhecimento da sua personalidade jurídica é uma consequência inata. Desta forma, não resta dúvida, o nascituro é uma pessoa desde sua concepção e iniciada a nidação, ele é titular de direitos, pois é uma pessoa que está por vir, e que não pode ser afastado de sua personalidade jurídica.

A proteção do direito à vida do nascituro, por meio da incriminação do aborto, o bem jurídico protegido não é outro senão à vida da pessoa que está por vir, não obstante a morte 
intrauterina, de forma intencional, a monta da pena é consideravelmente menor daquela em que é retirada a vida de uma pessoa já nascida. Contudo, primordialmente tutela-se 0 direito à vida, e essa peculiaridade em nada afasta a atribuição de pessoa ou até mesmo a importância do nascituro, porque se assim fosse o crime de homicídio, que fica mui aquém da pena crime de latrocínio, perderia seu valor ou sua essência. Com razão não há de se ter qualquer desprezo àquele bem jurídico tutelado, pois a vida é um direito pelo qual todos os outros decorrem, isto é, nada adiantaria sem esta, tamanha é a sua importância.

A tutela do direito à liberdade é reconhecida, ainda que incipiente, ao nascituro, pois não existe razão coerente - já que se trata pessoa -, para afastá-lo do rol de sujeitos descritos no texto constitucional, mais precisamente no art. 5ำ, caput. Assim, ao nascituro é titular dos direitos fundamentais, devendo valer-se dos tais diante das violências, ameaças e até mesmo omissões do Poder Estatal, pois estes têm o condão de limitação a este último. Ademais, a Convenção Americana sobre os Direitos Humanos e a Declaração Universal dos Direitos Humanos, são normas com eficácia no ordenamento jurídico brasileiro, por conta do art. $5^{\circ}$, $\S 2^{\circ}$, da Constituição, que tem como um dos fundamentos que "todas as pessoas nasçam livres e iguais em dignidade e direitos".

Destarte, persistente é a dúvida; pode uma pessoa nascer livre cercada por grilhões, em ambientes opressores e insalubres, como no caso do nascituro e sua genitora em situação carcerária? Certamente que está sendo tolhido o direito do nascituro nascer livre, bem como, o seu direito a um desenvolvimento saudável, o direito à vida, e ante a estas agressões o habeas corpus se faz necessário, sendo uma via adequada para assegurar o direito de nascer livre a pessoa que está por vir. Uma garantia constitucional consagrada no art. 5ำ da Carta Magna e, portanto, cláusula pétrea, na forma do art. $60, \S 4^{\circ}$, do mesmo texto.

E mais, considerando 0 princípio basilar do direito penal, o princípio da intranscendência pena, onde, em breves palavras, a penalidade não passará da pessoa do condenado, expresso também no art. $5^{\circ}$ da Constituição, concluímos que, o nascituro não pode estar sendo condenado com sua genitora, e assim ficar à mercê da própria sorte, 
simplesmente porque se encontra enleado a ela, pois este entendimento não é a vertente adotada pelo ordenamento jurídico, e, na ausência do poder familiar da gestante ao nascituro, lhe é conferido um tutor, conforme já mencionamos. Assim se sua genitora não se encontra em sã consciência, a lei lhe confere direitos de ser amparado por outrem, reconhecendo assim a diferenciação entre estes - entre o nascituro e a genitora. Deste modo, o Estado deve se curvar a isto, e reconhecer que o nascituro e a sua genitora são pessoas distintas, titulares de direitos diversos, cabendo ao mesmo o cumprimento do ordenamento e princípios do Direito Brasileiro.

Nesse sentido, uma pessoa que está por vir merece ser reconhecida em sua dignidade, pois sua distinção com uma pessoa recém-nascida não the afasta o seu valor, muito menos a sua dignidade. Diante disso, temos por esclarecidos os principais direitos do nascituro e sua natureza jurídica, bem como, o seu exercício ao direito à liberdade, visto que se trata de pessoa, sujeito de direito. A despeito de não ter capacidade, o nascituro deve ser representado para valer-se dos seus direitos fundamentais quanto os da personalidade jurídica, que são the resguardados desde o momento de sua concepção no ventre materno. E este entendimento reflete no julgamento de casos concretos. Devendo assim, caso o nascituro encontre privado de seu direito de nascer livre, em razão de sua genitora estar cumprindo pena restritiva de liberdade, a medida eficaz é o habeas corpus, qual visa a garantir direito à liberdade, e ainda os dispostos na legislação constitucional e infraconstitucional.

Acrescenta-se, ainda, caso haja resistência dos doutos juristas e aplicadores do direito a esse entendimento explanado, seja empregado a razoabilidade e a proporcionalidade, para mantença da prisão da genitora do nascituro, todavia, temperada com o regime diferenciado, a exemplo o da prisão domiciliar, a qual corrobora com a dignidade do nascituro.

Entendimento que, recentemente, fora objeto da Lei $\mathrm{n}^{\circ}$ 13.257, de 2016, qual alterou o art. 318, do Código Processo Penal, para substituir a prisão preventiva pela domiciliar quando a mulher encontrarse gestante, ou tiver filho menor de 12 anos, inclusive ao pai, quando encontra-se nesta última hipótese. 
Ainda, este é o entendimento da segunda turma do Supremo Tribunal Federal, no Julgamento do Habeas Corpus n. 143641, qual decidiu pela substituição da prisão preventiva pela domiciliar, para a mulher presa gestante, tendo como fundamento a dignidade do nascituro.

\section{REFERÊNCIAS}

ALENCAR. Ana Júlia Couto de. Humanização de Procedimentos de Saúde: Caminhos Possíveis. Jan. a abr. 2001. Disponível em: < http://www.socep.org.br/Rped/pdf/2.1\%200pn\%20Med.pdf> Acesso em 1/1/2015 as 05:25 hs.

ALMEIDA. Silmara J. A. Chinelato e. Tutela civil do nascituro. São Paulo: 2000.

ARAÚJO. Martha Chavedar de Souza. Direito à Vida em Peter Singer e a tradição utilitária. 2008. Disponível em: http://www.uece.br/cmaf/dmdocuments/Dissertacoes2008_direito_Vida_Peter_Singe r.pdf > Acesso em 1/1/2015 as 09:57 hs.

BARROSO, Luís Roberto. Interpretação e aplicação da constituição. São Paulo: Saraiva, 1999.

BEVILÁQUA, Clóvis. Comentários ao Código Civil dos Estados Unidos do Brasil. Rio de Janeiro: Rio, 1975.

BRASIL. Constituição da República Federativa do Brasil. Diário Oficial da União, Poder Legislativo, Brasília, DF, 05 jan. 1988. Disponível em: $<$ http://www.planalto.gov.br> Acesso em 1/4/2015 as 08:55 hs.

BRASIL. Código Civil. Lei no 10.406. Diário Oficial da União, Poder Legislativo, Brasília, DF, 10 jan. 2002. Disponível em: <http://www.planalto.gov.br > Acesso em 1/4/2015 as 09:55 hs.

BRASIL. Código Penal. Lei no 2.848. Diário Oficial da União, Poder Legislativo, Brasília, Rio de Janeiro, RJ, 7 dez. 1940. Disponível em: <http://www.planalto.gov.br $>$ Acesso em 1/4/2015 as 09:45 hs.

BRASIL. Código Processo Civil. Lei no 5.869. Diário Oficial da União, Poder Executivo, Brasília, DF, 11 jan. 1973. Disponível em: <http://www.planalto.gov.br > Acesso em 5/4/2015 as 08:10 hs.

BRASIL. Código Processo Penal. Lei no 3.689. Diário Oficial da União, Poder Executivo, Rio de Janeiro, RJ, 03 out. 1947. Disponível em: <http://www.planalto.gov.br > Acesso em 5/4/2015 as 08:10 hs. 
BRASIL. Estatuto da Criança e do Adolescente. Lei. 8.069. Diário Oficial da União, Poder Legislativo, Brasília, DF, 13 jul. 1990. Disponível em: <http://www.planalto.gov.br > Acesso em 2/4/2015 as 09:45 hs.

BRASIL. Lei n. 8.560. Diário Oficial da União, Poder Legislativo, Brasília, DF, 29 dez. 1992. Disponível em: <http://www.planalto.gov.br > Acesso em 2/1/2015 as 09:14 hs.

BRASIL. Lei n. 9.434. Diário Oficial da União, Poder Legislativo, Brasília, DF, 4 fev. 1997. Disponível em: <http://www.planalto.gov.br > Acesso em 1/4/2015 as 09:10 hs.

BRASIL. Lei n. 11.804. Diário Oficial da União, Poder Legislativo, Brasília, DF, 5 nov. 2008. Disponível em: <http://www.planalto.gov.br> Acesso em 2/4/2015 as 09:10 hs.

BRASIL. SUPREMO TRIBUNAL FEDERAL. RE: 99038 MG, Relator: Min. FRANCISCO REZEK, Data de Julgamento: 18/10/1983, SEGUNDA TURMA, Data de Publicação: DJ 05-10-1984 PP-16452 EMENT VOL-01287-02 PP-00673.

BRASIL. SUPREMO TRIBUNAL FEDERAL. ADPF: 54 DF, Relator: Min. MARCO AURÉLIO, Data de Julgamento: 27/04/2005, Tribunal Pleno, Data de Publicação: DJe092 DIVULG 30-08-2007 PUBLIC 31-08-2007 DJ 31-08-2007 PP-00029 EMENT VOL02287-01 PP-00021.

BRASIL. SUPREMO TRIBUNAL FEDERAL. ADI: 3510 DF, Relator: Min. CARLOS BRITTO, Data de Julgamento: 17/04/2007, Data de Publicação: DJ 23/04/2007 PP00020.

BRASIL. SUPERIOR TRIBUNAL DE JUSTIÇA. REsp: 399028 SP 2001/0147319-0, Relator: Ministro SÁLVIO DE FIGUEIREDO TEIXEIRA, Data de Julgamento: 26/02/2002, T4 - QUARTA TURMA, Data de Publicação: DJ 15.04.2002 p. 232 RSTJ vol. 161 p. 395 RT vol. 803 p. 193.

BRASIL. TRIBUNAL REGIONAL DO TRABALHO DO RIO GRANDE DO SUL, ACÓRDÃO 0182900-57.2009.5.04.0661 RO, Relator DESEMBARGADOR CLÁUDIO ANTÔNIO CASSOU BARBOSA, Data do Julgamento: 10/11/2011.

BRASIL. ESPÍRITO SANTO - TRIBUNAL DE JUSTIÇA, HC. 100070002991 ES 100070002991, Relator: DESEMBARGADOR ADALTO DIAS TRISTÃO, Data de Julgamento: 28/03/2007, SEGUNDA CÂMARA CRIMINAL, Data de Publicação: 09/05/2007.

BRASIL. SANTA CATARINA - TRIBUNAL DE JUSTIÇA, AC: 20140324666 SC 2014.032466-6, Relator: SÉRGIO IZIDORO HEIL, Data de Julgamento: 21/01/2015, QUINTA CÂMARA DE DIREITO CIVIL JULGADO.

COMPARATO, Fábio Konder. A afirmação histórica dos diretos humanos. $5^{\circ}$. ed. rev. e atual. - São Paulo: Saraiva, 2007.

DINIZ, Maria Helena. Curso de direito civil Brasileiro, volume 1: teoria geral do direito civil. 28 ․ ed. - São Paulo: Saraiva, 2011. 
DECLARAÇÃO UNIVERSAL DOS DIREITOS HUMANOS. Adotada e proclamada pela resolução 217 A (III) da Assembleia Geral das Nações Unidas em 10 de dezembro de 1948. Disponível na Biblioteca Virtual de Direitos Humanos da Universidade de São Paulo <www.direitoshumanos.usp.br> Acesso em 3/1/2015 as 09:19 hs.

DECLARAÇÃO DOS DIREITOS DO HOMEM E DO CIDADÃO, Proclamada pela Assembléia Nacional Francesa em 26 de agosto de 1789. Disponível na Biblioteca Virtual de Direitos Humanos da Universidade de São Paulo $<$ www.direitoshumanos.usp.br> Acesso em 3/1/2015 as 08:19 hs.

DWORKIN, Ronald. Domínio da vida: aborto, eutanásia e liberdades individuais. Tradução Jefferson Luiz Camargo; revisão da tradução; Silvana Vieira - 2. ed.- São Paulo: Editora WMF Martins Fontes, 2009. - (Biblioteca jurídica WMF).

GAGLIANO. Pablo Stolze; PAMPLONA FILHO. RODOLFO. Novo curso de Direito civil, volume 1: parte geral. 13ํ․ ed. - São Paulo: Saraiva, 2011.

GONÇALVES, Carlos Roberto. Direito Civil Brasileiro, volume 1: parte geral.9. ed. - São Paulo: Saraiva, 2011.

GRECO. Rogério. Curso de Direito Penal: parte geral. - 13‥ ed. Rio de Janeiro: Impetus, 2011.

LAKATOS, Eva Maria; MARCONI, Marina de Andrade. Metodologia cientifica. 4º ed. - São Paulo: Atlas, 2004.

MIRABETE, Júlio Fabbrini; FABBRINI. RENATO. Manual de direito penal, volume 1: parte geral, arts. $1^{\circ}$ ao 120 do CP. 29․ ed. rer. e atual até 10 de janeiro de 2013. - São Paulo: Atlas, 2013.

PACTO SÃO JOSÉ DA COSTA RICA. Adotada e aberta à assinatura na Conferência Especializada Interamericana sobre Direitos Humanos, em San José de Costa Rica, em 22.11.1969. Disponível na Biblioteca Virtual < http://www.pge.sp.gov.br/centrodeestudos/bibliotecavirtual/instrumentos/sanjose.htm $>$ Acesso em 2/3/2015 as 10:18 hs.

PEREIRA. Caio Mário da Silva. Instituições do Direito Civil. 21ํ. ed. Rio de Janeiro: Forense, 2005.

CENTRO PELA JUSTIÇA E PELO DIREITO INTERNACIONAL, CEJIL. ASSOCIAÇÃO JUÍZES PARA A DEMOCRACIA, AJD. INSTITUTO TERRA, TRABALHO E CIDADANIA, ITCC. PASTORAL CARCERÁRIA NACIONAL. INSTITUTO DE DEFESA DO DIREITO DE DEFESA, IDDD. CENTRO DANDARA DE PROMOTORAS LEGAIS POPULAR. ASSOCIAÇÃO BRASILEIRA DE DEFESA DA MULHER, DA INFÂNCIA E DA JUVENTUDE. ASBRAD. COMISSÃO TEOTÔNIO VILELA, CTV. INSTITUTO BRASILEIRO DE CIÊNCIAS CRIMINAIS, IBCCRIM. Relatório sobre Mulheres Encarceradas. 2007. Desenvolvido pela Comissão Interamericana dos Direitos Humanos. Disponível em: 
<http://www.ajd.org.br/noticias_ver.php?idConteudo=681> Acesso em 1/3/2015 as $4: 20$ hs.

RODRIGUES, Silvio. Direito Civil, volume 1: parte geral. 34ํ․ ed. São Paulo: Saraiva 2003.

VENOSA. Sílvio de Salvo. Direito Civil: parte geral. 8‥ ed. São Paulo: Atlas, 2008

Recebido em: 15/06/2016

Aprovado em: 02/03/2017 